\title{
Comunicación de un destino experiencial a través de las páginas web. Análisis de Villavicencio - Colombia*
}

\author{
Communicating an Experiential Destination through Web Pages. Analysis of Villavicencio, Colombia \\ Comunicação de um destino experiencial através dos sites. Análise de Villavicencio - Colômbia
}

\author{
Maria Cristina Otero Gómez ${ }^{\mathrm{a}}$ \\ Universidad de los Llanos, Colombia \\ motero@unillanos.edu.co \\ ORCID: http://orcid.org/0000-0002-3241-7877 \\ Claudio Fabián Centocchi \\ Universidad de Buenos Aires, Argentina \\ ORCID: http://orcid.org/0000-0001-9637-6309 \\ Wilson Giraldo Pérez \\ Universidad de los Llanos, Colombia \\ ORCID: http://orcid.org/0000-0001-8514-9805
}

DOI: https://doi.org/10.11144/Javeriana.syp37-73.cdep Redalyc: http://www.redalyc.org/articulo.oa?id=86058735003

Fecha de recepción: 06 Junio 2017 Fecha de aprobación: 25 Septiembre 2018

Fecha de publicación: 30 Diciembre 2018

\section{Resumen:}

El objetivo de este artículo es analizar la comunicación que se hace de Villavicencio como destino turístico experiencial, orientada al segmento internacional, a través de las páginas web. Se ha realizado una revisión de la literatura para comprender cómo interactúan los turistas con estas páginas y cómo la información contenida en ellas contribuye en alcanzar la satisfacción gracias a la oferta comunicada. Se realizó una investigación mixta en la cual, por un lado, se aplicaron 156 encuestas, de las cuales se analizaron 33 , correspondientes a los turistas que recurrieron al uso de sitios web y, por el otro, se examinaron 15 páginas web. Para el análisis cuantitativo se empleó el software SPSS V18; y para el análisis cualitativo, un abordaje semiótico. Los resultados demostraron que, a pesar de las deficiencias comunicacionales, principalmente en los sitios web oficiales, imperan las calificaciones positivas por parte de los turistas.

Palabras clave: comunicación, marketing turístico, imagen.

\begin{abstract}
:
This work aims to analyze how the city Villavicencio is communicated as an experiential tourism destination, targeting foreign tourists through webpages. A literature review was carried out to understand how tourists are interacting with these webpages and how the information in them contributes to the reader's satisfaction thanks to the communicated offer. A combined research was conducted where 156 interviews were completed. Out of them, 33 were analyzed as they indicated that the tourist used the webpages. On the other hand, 15 webpages were also examined. The software SPSS V18 was used in the quantitative analysis, while a semiotic approach was used in the qualitative analysis. The results showed that despite the communicative deficiencies, mostly in the official websites, there is a prevalence of positive ratings by the tourists.
\end{abstract}

Keywords: communication, tourism marketing, image.

\section{Resumo:}

O objetivo deste artigo é analisar a comunicação feita sobre Villavicencio como destino turístico experiencial, orientada ao segmento internacional através dos sites. Revisão de literatura foi realizada para compreender como interagem os turistas com estes sites e como a informação conteúda neles contribui para alcançar a satisfação graças à oferta comunicada. Realizou-se pesquisa mista na qual, por um lado, foram aplicados 156 inquéritos, dos quais analisaram-se 33, correspondentes a turistas que recorreram ao uso de sites e, por o outro, 15 sites foram examinados. Para a análise quantitativa empregou-se o software SPSS V18 e para a análise qualitativa, uma abordagem semiótica. Os resultados demostraram que, apesar das deficiências comunicacionais, principalmente nos sites oficiais, prevalecem qualificações positivas por parte dos turistas.

Notas de autor: 
Palavras-chave: comunicação, marketing turístico, imagem.

\section{Introducción}

En la actualidad, el turismo es considerado un fenómeno socioeconómico que supera las tradicionales leyes de oferta y demanda. Surgen conceptualizaciones que trascienden los aspectos netamente cuantificables que se miden a partir del número de visitantes y el margen de ganancias obtenido (Aguiar, 2012), para dar lugar a otros enfoques que incluyen la experiencia como elemento que brinda satisfacción al sistema emocional del turista (Bordas, 2003; Kotler, Bowen y Makens, 2004).

Desde esta perspectiva, los turistas consideran las vacaciones un período que les brindan emociones y que les permiten estar, según Csikszentmihalyi (1975), en un estado de flow, es decir, que el sujeto se encuentra completamente absorbido por una actividad durante la cual pierde la noción del tiempo y experimenta una enorme satisfacción.

Obviamente, para alcanzar ese estado, el destino debe garantizar que se aleja de una oferta convencional de servicios turísticos, enfocándose en las características diferenciales del territorio, el patrimonio, el paisaje, la cultura y las señas de identidad de las poblaciones anfitrionas (Rivera, 2013). La oferta de servicios turísticos, aun siendo de calidad, ya no es suficiente para conseguir la satisfacción plena y el bienestar psicológico de los turistas (Cuenca y Prat, 2012). Estos visitantes también buscan la interacción social (De Rojas y Camarero, 2008), vivir la vida de los "nativos", acceder a sus lugares de ocio y adaptarse a su gastronomía, folclore y ritmo (Funes, 2015). De esta manera, el turismo se convierte en un generador de experiencias orientadas al consumidor.

Los postulados anteriores podrían explicar las razones por las cuales en Villavicencio (Colombia) ha aumentado recientemente el número de turistas extranjeros. Esta ciudad es un destino que carece de posicionamiento internacional; no obstante, se evidencia en el presente estudio la visita de personas procedentes de países tan lejanos e insospechados como Suiza, Holanda, Rusia, entre otros. Como resultado de esta dinámica, se ha considerado indagar: ‘a través de qué medio el turista se entera de su existencia?, ¿cuál es la percepción acerca de la oferta promocionada en las diferentes páginas web? y ¿cuál es su nivel de satisfacción con la oferta promocionada?

Estos interrogantes se plantean por considerar que Villavicencio es un destino turístico que se encuentra en lo que Butler (1980) denomina la etapa de implicación dentro del ciclo de vida del producto turístico. Según Garay (2007), esta etapa consiste en que las iniciativas locales, en cuanto a desarrollo de planta turística, comunicación y promoción, tienen como resultado que el número de visitantes que elige el destino se eleve.

Pese a que cerca de Villavicencio se encuentran poblaciones con características similares, que también comunican la promesa de vivir un turismo experiencial, ésta es la ciudad que más flujo de turistas extranjeros recibe en la región de la Orinoquía colombiana, lo que se convirtió en otro argumento para avanzar en este estudio, pues, como afirman Medina, Rey y Rufín (2010), "actualmente hay una creciente competencia generada por la proliferación de rutas, lo que ocasiona que el turista pueda elegir entre un mayor número de posibilidades" (p. 279). Como se desconocen las razones por las cuales los turistas internacionales seleccionan a Villavicencio por encima de los demás destinos, este estudio tiene por objetivo analizar la comunicación que se hace de Villavicencio como destino turístico experiencial, orientada al segmento internacional a través de las páginas web. 


\section{Revisión de literatura}

\section{Promoción de un destino turístico}

La promoción de un destino, según la definición de Ejarque (2005), consiste en comunicar a los potenciales consumidores-turistas que la oferta propuesta es capaz de satisfacer sus exigencias y sus demandas; en definitiva, es tratar de convencerlo que merece la pena ir allí.

Dicha promoción no pasa sólo por la existencia de atractivos turísticos, también pasa por la forma en que estos son difundidos (Marujo, 2012). Ello se debe a que una adecuada comunicación puede proporcionar una serie de recursos al sector turístico que permiten combatir la estacionalidad y promover su sostenibilidad (Jiménez, Coca, Gutiérrez y Fernández, 2016). En este sentido, investigadores como Mendes, Biz y Gândara (2013) atribuyen gran responsabilidad de la planificación, gestión y promoción del turismo a los poderes públicos y privados en cuanto a la producción, organización, distribución y gestión de información turística relevante para las personas interesadas en conocer el destino.

En este proceso, desempeñan un papel fundamental las imágenes que integran las estrategias de promoción y comunicación. Galí y Donaire (2005) proponen la existencia de las imágenes turísticas emitidas, definidas como una reproducción de signos cuyos significados han estado socialmente construidos y diseminados. Dentro de la categoría de imágenes emitidas se encuentran las imágenes inducidas, las cuales, según Miossec (1977), son aquellas que han sido promovidas a partir de acciones de marketing, por tanto, serán consideradas para el desarrollo del presente artículo debido a su aporte en la divulgación de una imagen turística. También es necesario precisar que Camprubí, Guia y Comas (2009) son enfáticos en su pronunciamiento sobre la coherencia que debe existir entre la imagen turística inducida y el producto turístico ofrecido.

Actualmente, los avances tecnológicos llevan a fortalecer la interacción entre el turismo y las redes informáticas. Según Burgess, Parish y Alcock (2011), la información de la industria turística y de viajes juega un papel fundamental para la tecnología web en la promoción y comercialización de destinos turísticos. Esto se debe, en parte, a que los entornos virtuales facilitan la memorización de la información turística (Wang y Yang, 2008) e influyen mejor en las expectativas de los turistas (Pantano y Servidio, 2011). Por esta razón, el contenido, la calidad y la efectividad de las páginas de internet es de suma importancia dentro del proceso de comercialización (Cabanilla y Gentili, 2015).

De hecho, autores como Chiou, Wan y Lee (2008) sostienen que Internet presenta la información visual del lugar turístico de manera eficiente, por lo que los consumidores podrían preferirlo en vez de las guías o folletos turísticos tradicionales.

\section{El turismo experiencial}

Para algunos individuos, la búsqueda de aventuras, la exposición al riesgo de explorar lo desconocido y el hecho de vivir nuevas experiencias se convierten en motivadores para emprender largos trayectos. Pine y Gilmore (1998) consideran que la evaluación del turismo experiencial se ve afectada por factores como la experiencia propiamente dicha, los servicios, el lugar y la infraestructura que brinde la oferta. Estos autores propusieron una taxonomía de la experiencia del turista basado en dos dimensiones. Por un lado, se encuentra la participación activa vs pasiva del consumidor con la oferta; por otro, está la conexión del consumidor con el medio ambiente, representada en la capacidad de inmersión vs. absorción, tal como se muestra en la tabla 1 . 
TABLA 1.

Clasificación de la experiencia

\begin{tabular}{|c|c|c|c|}
\hline $\begin{array}{l}\text { Dimensiones de } \\
\text { participación del } \\
\text { consumidor }\end{array}$ & Campo & Experiencia & Oferta \\
\hline $\begin{array}{l}\text { Participación pasiva } \\
\text { y absorción }\end{array}$ & Entretenimiento & $\begin{array}{l}\text { El consumidor absorbe } \\
\text { pasivamente lo que está } \\
\text { sucediendo }\end{array}$ & $\begin{array}{l}\text { Festivales de } \\
\text { música y demás } \\
\text { eventos }\end{array}$ \\
\hline $\begin{array}{l}\text { Participación activa y } \\
\text { absorción }\end{array}$ & Educación & $\begin{array}{l}\text { Aprender algo nuevo basado } \\
\text { en el sentido de } \\
\text { "aprendizaje" que se absorbe, } \\
\text { pero también requiere una } \\
\text { participación activa }\end{array}$ & $\begin{array}{l}\text { Clases de } \\
\text { gastronomía }\end{array}$ \\
\hline $\begin{array}{l}\text { Participación activa e } \\
\text { Inmersión activa }\end{array}$ & Escapismo & $\begin{array}{l}\text { La experiencia se basa en } \\
\text { "divergir hacia un nuevo yo" } \\
\text { basada en el sentido de } \\
\text { "hacer", donde el cliente se } \\
\text { involucra en lo que está } \\
\text { sucediendo y participa } \\
\text { activamente }\end{array}$ & $\begin{array}{l}\text { Ciclismo de } \\
\text { montaña }\end{array}$ \\
\hline $\begin{array}{l}\text { Participación pasiva } \\
\text { e inmersión pasiva. }\end{array}$ & La estética & $\begin{array}{l}\text { Los consumidores o los } \\
\text { participantes están inmersos } \\
\text { en una actividad o entorno, } \\
\text { pero ellos tienen poco o } \\
\text { ningún efecto en ella. }\end{array}$ & $\begin{array}{l}\text { Avistamiento de } \\
\text { aves u } \\
\text { observación desde } \\
\text { un mirador o } \\
\text { paraje. }\end{array}$ \\
\hline
\end{tabular}

Fuente: adaptación de The four realms of an experience (Pine y Gilmore, 1998, p. 102)

Las dimensiones anteriores han sido analizadas y aceptadas desde diferentes enfoques del turismo: se destacan en tal sentido las investigaciones de Quadri-Felitti y Fiore (2012), Mehmetoglu y Normann (2013) y $\mathrm{Su}$ et al. (2016). Todos ellos reconocen mediante evidencia empírica que las experiencias agradables y memorables de los turistas en el destino dependen de cuán activo está un consumidor en el proceso de producción y consumo de la experiencia.

\section{Metodología}

El presente análisis se desarrolló a partir de un modelo mixto, el cual es definido por Johnson y Onwuegbuzie (2004) como “(...) el tipo de estudio donde el investigador mezcla o combina técnicas de investigación, métodos, enfoques, conceptos o lenguaje cuantitativo o cualitativo en un solo estudio" (p. 17).

\section{Análisis cuantitativo}

En la fase cuantitativa se hizo uso de los métodos estadísticos para efectuar los diseños muestrales conducentes a la generación de inferencias poblacionales, siguiendo el método inductivo. 


\section{Fuentes de información}

La investigación se hizo en Villavicencio - Colombia. Se reunió información primaria mediante encuestas aplicadas a 156 turistas internacionales, de los cuales 33 utilizaron el entorno web para adquirir información acerca de Villavicencio como destino turístico. La encuesta se diseñó con preguntas de escala Likert y fue sometida a un proceso de validación en campo que garantizó la confiabilidad del instrumento. El proceso de validación obtuvo un indicador de 0,9 en el Alfa de Cronbach.

Algunas encuestas se aplicaron in situ durante los años 2015 y 2016, en el desarrollo de los siguientes eventos: el Campeonato Mundial de Aparte y Encierro de Ganado, el Torneo Internacional del Joropo, el Encuentro Mundial del Coleo, el Festival Llanero de Villavicencio y la Feria Expo Malocas. Otras encuestas se aplicaron durante los períodos en los que no se efectuaron eventos masivos. También se enviaron encuestas en línea a las personas que visitaron la ciudad en el año 2014.

\section{Procesamiento de las encuestas}

Para la realización de los análisis descriptivos e inferenciales, se utilizó el software SPSS V.18. En los análisis inferenciales se ejecutaron las correlaciones de Tau-c de Kendall, lo que permitió identificar las asociaciones entre la variable edad y las variables medida global de la percepción del destino a través del uso de páginas web y la satisfacción con la experiencia turística luego de que ésta finaliza.

\section{Análisis cualitativo/semiótico}

La cultura es una red infinita de sentidos; los individuos la alimentan constantemente mediante la recepción/ generación de discursos. La semiótica, con el apoyo de otras disciplinas, es la principal encargada de estudiar los procesos de producción de significación que dinamizan lo social. El inevitable desfase entre las instancias de producción (oferta) y de reconocimiento (demanda), que revela la circulación del sentido, requiere que se aborde desde el punto de vista metodológico a partir de la complementariedad entre el análisis semiótico y el trabajo de campo (Verón, 1985).

Un análisis semiótico sin datos de campo se muestra incompleto ya que permite conocer en detalle las propiedades de cierto conjunto discursivo, pero ignora si se adecúa o no con los intereses, expectativas e imaginarios de los consumidores. A la inversa, los datos de campo sin conexión con un análisis semiótico representan respuestas "rudimentarias" que se desprenden de fenómenos significantes que no se toman en cuenta pese a que han condicionado/impulsado la generación de tales reacciones. La indeterminación relativa del sentido obliga, por consiguiente, a comprender la relación entre ambas lógicas, lo que implica la superación de la idea de que integran realidades separadas (Verón, 1985).

\section{Fuentes de información}

Se recortó como corpus 15 páginas web cuyos emisores responsables son organizaciones gubernamentales (dependencias del municipio) o comerciales (empresas de servicios turísticos), interesadas de modo directo en la sustentación tanto material como simbólica del lugar.

La marca destino Villavicencio constituye, en definitiva, una red de significados que se cimienta a partir de discursos de operadores influyentes. Es por ello que se han seleccionado estas unidades de análisis de naturaleza híbrida, que combinan el registro verbal con el icónico, y que se dirigen al visitante potencial. 


\section{Examen del corpus}

La indagación semiótica siguió el enfoque de Steimberg (1993), quien define lo temático, lo retórico y lo enunciativo como tres niveles de análisis de tipos de rasgos (estrategias) útiles para la descripción de un corpus.

La dimensión temática (semántica) abarca los modos de construcción de los universos de referencia; se liga con los asuntos tratados que se construyen a partir de la articulación de motivos (unidades mínimas de significado) (Segre, 1985). La dimensión retórica alude a las diversas maneras de configuración discursiva: incluye, por ende, las operaciones figurales (observación micro), como las grandes articulaciones morfológicas (observación macro). La dimensión enunciativa, retomando los resultados del análisis de los niveles anteriores, especifica los perfiles del enunciador/argumentador y del enunciatario/destinatario que se plasma en los discursos, así como el vínculo o contrato que se establece entre ellos.

\section{Hipótesis}

Según Castillo y Castaño (2015), "la percepción de las imágenes por segmentos diferentes de mercado (edad, orígenes geográficos y culturales), ayudaría a comprender cómo optimizar la comunicación de un destino turístico" (p. 743). De este modo, la heterogeneidad de los turistas conlleva a que las motivaciones del viaje sean percibidas de diferentes maneras. Varias investigaciones empíricas demuestran que los aspectos sociodemográficos influyen significativamente en la imagen percibida (Chen y Kerstetter, 1999; Bhatnagar y Ghose, 2004; Serre y Chevalier, 2012; Ari, Subramoniana y Pahlevan, 2014). A partir de estos aportes, se desprenden las siguientes hipótesis que se testean en la presente investigación:

H1: La edad del consumidor tiene una relación directa y positiva sobre la percepción de la oferta turística que se comunica a través de las páginas web.

H2: La edad del consumidor turístico tiene una relación directa y positiva sobre la satisfacción alcanzada al finalizar su experiencia turística.

\section{Resultados}

\section{Descripción de las fuentes de información utilizadas por los turistas internacionales}

Según los resultados del estudio, las principales fuentes de información sobre el destino que apelaron los turistas fueron: el voz a voz, con el 34\%; las páginas web de las entidades públicas y privadas encargadas de promocionar a Villavicencio junto con los buscadores de viajes, con el 21\%; los líderes de opinión, con el 5\%; los documentales, las películas o telenovelas, con el 3\%; y las redes sociales, con el 2\%. También se consultó sobre la iniciativa propia, la cual obtuvo el 18\%; y, finalmente, la combinación de varias fuentes, que representó el $17 \%$.

Pese a que el voz a voz ocupó el primer lugar, esta fuente se descarta como tema de análisis en la presente investigación debido a que no constituye una estrategia de comunicación manipulable e intencional por parte del oferente. Por ello, nos centramos en las páginas web, en razón a que fueron la fuente consultada por dos de cada diez turistas que visitaron la ciudad. 


\section{Categorización de la oferta por Internet}

A partir de la revisión de páginas web que promocionan a Villavicencio, se pudo establecer que su encuadre dentro del turismo experiencial se apoya principalmente en la referencia a tres grandes materias: la naturaleza, la cultura local y el ocio.

En la categoría de turismo de naturaleza, se impulsan las experiencias asociadas con caminatas, atravesar puentes colgantes de madera y bañarse en cascadas cristalinas. Adicionalmente, se incluye la observación del paisaje que comprende especies endémicas tanto de flora como de fauna. Estos recorridos pueden hacerse a pie, a caballo o en bicicleta, según las condiciones climáticas.

Respecto al turismo cultural, Villavicencio es definido como un espacio donde por años ha existido la interculturalidad, lo que ha permitido la convivencia de varios grupos, entre los que se destacan los indígenas, mestizos o colonos, y negros. En cuanto a las tradiciones, el folclore llanero tiene un lugar destacado en sus habitantes: sobresalen la música, la danza, el vestuario y el coleo (deporte autóctono). Además, la comida típica presenta un plato emblemático reconocido ampliamente en Colombia y Venezuela; se trata de la "mamona o carne a la llanera", existen en las zonas urbana y rural múltiples asaderos en donde se exhibe el ritual de su preparación. Los entes gubernamentales invitan a los turistas nacionales y extranjeros a participar en los eventos culturales que se realizan en diferentes épocas del año.

Acerca del ocio, la promoción destaca el clima cálido y soleado durante largas temporadas, lo que favorece las actividades al aire libre. Entre la oferta turística se encuentran miradores ubicados en la cordillera oriental que permiten divisar la inmensidad de la llanura; estos sitios son visitados por los turistas internacionales, en especial al atardecer, para contemplar la puesta del sol. También existe el Bioparque Los Ocarros, donde se hallan especies de animales endémicos que han sido rescatados del cautiverio y no pueden reintegrarse a la vida silvestre.

Sumado a esto, se da a conocer que en la ciudad o en sus alrededores hay zonas privadas donde es posible realizar cabalgatas, parapente, canopy, rapel y balsaje por río, junto con el ofrecimiento de pernoctar en camping.

La tabla 2 lista algunas páginas promocionales que, según las propuestas que invitan a hacer, tiende a inscribirse en al menos una de las categorías reseñadas. 
TABLA 2.

Sitios Web de promoción turística de Villavicencio - Colombia

\begin{tabular}{ll}
\hline Categoría & Sitio Web \\
\hline & http://www.turismovillavicencio.gov.co/site/ \\
& https://www.tripadvisor.co \\
Turismo de naturaleza & http://campoecologicogramalote.com/promo/ \\
& https://www.villavicencio.gov.co/ \\
& http://www.panoramio.com \\
\hline & http://www.turismovillavicencio.gov.co/site/ \\
& http://www.viajaporcolombia.com/ \\
& http://www.colombia.travel/es/a-donde- \\
& ir/orinoquia/villavicencio \\
& http://www.turismometa.gov.co/ \\
Turismo cultural & http://www.viajesoxigeno.com \\
& http://www.colombiadeportesextremos.com \\
& http://www.aventureros.co \\
& http://www.vivecolombia.travel/es/ \\
& http://dosisverde.com/ \\
& http://www.parapentevillavicencio.com/es \\
\hline
\end{tabular}

Fuente: elaboración propia

\section{La promoción de Villavicencio como destino turístico experiencial: una aproximación semiótica}

En el punto anterior se presentó un abordaje inicial a la oferta comunicacional de acuerdo con los contenidos: naturaleza, cultura local y ocio son los pilares que componen la promesa turística experiencial villavicense. Este destino se configura como una opción atractiva donde se entrecruzan una naturaleza y una cultura potentes.

Del lado de la naturaleza se ofrece el disfrute de dos ambientes diferentes: la planicie y la montaña, con sus especies y paisajes característicos. En ambos hábitats, los turistas tienen la posibilidad de desempeñar una participación tanto activa como pasiva, acorde con lo planteado en la tabla 1. La primera se halla estimulada fundamentalmente por los sitios web de operadores privados, quienes de esa forma amasan sus ganancias.

La expectativa consiste en vivir una sucesión de momentos adrenalínicos de libertad y aventura, en el aire, el agua o la tierra; en contacto con animales más familiares (bovinos, equinos) o extraños, en compañía de amigos o de la pareja. El entorno, más allá de sus divergencias, nunca aparece como un mero decorado, se erige como un actante objeto (Greimas, 1976) que merece ser recorrido y descifrado, es decir dominado.

Del lado de la cultura se distinguen también dos grandes tipos de propuestas. Por una parte, fomentado en gran medida por las páginas web públicas, se recomienda la visita a ciertos lugares de la ciudad. Parques, monumentos, fuentes y edificaciones que producen escaso encanto debido esencialmente a la utilización de estrategias retóricas fallidas: las fotos solitarias y distantes, así como los escritos cortos y apocados, fracasan en presentar a esos puntos como atracciones inusuales, imperdibles. En ello tampoco ayuda el hecho de que Villavicencio debió reconstruirse casi a pleno en razón a un incendio que lo consumió en 1890, una desgracia que le impide mostrar una infraestructura que revele "sin fingimiento" cómo fue antes de la última centuria.

La restante propuesta vinculada con lo cultural posee, en cambio, una vasta riqueza. Sin omitir la existencia de otros grupos, como ya fue indicado, este destino se vuelca a apropiarse empero casi con exclusividad de 
la idiosincrasia mestiza llanera. En tal sentido, los sitios web ponen énfasis en promocionar una serie de manifestaciones deportivas, musicales y gastronómicas que por su rareza, arrojo y júbilo pueden despertar la curiosidad del visitante foráneo.

Junto con los planes que permiten deleitarse con la naturaleza, las expresiones de la cultura llanera constituyen per se las propuestas más seductoras, a la vez que identificatorias, para poder incrementar el flujo turístico internacional. Sin embargo, las páginas web estudiadas, que se orientan a cumplir ese objetivo, necesitan mejorar su calidad; principalmente aquellas que proceden de dependencias de la administración pública, no solo porque sus comunicaciones exhiben mayores problemas, sino también porque debieran ser los máximos responsables de seguir un plan estratégico integral que procure difundir a los diversos colectivos y mercados (nacional e internacional), los valores de la marca Villavicencio.

Las flaquezas de estos hipertextos se ubican en los niveles retórico y enunciativo; los organismos oficiales, ante todo, descuidan la dimensión persuasiva inherente a esta clase de discursos. No basta con informar -de manera generosa-, hay que esforzarse por convencer y conmover al usuario potencial. El enunciador tiene que destilar sabiduría, seguridad, confianza, apasionamiento. Para ello, Internet abriga un abanico extendido de recursos con el cual valerse en la producción de textos híbridos en pos de que el destinatario se convierta a fin de cuentas en un usuario efectivo.

\section{Un caso confirmatorio: los videos publicitarios del Festival Llanero 2016}

Como nunca, la mediatización cumple un papel fundamental en la configuración de la mirada turística (Urry, 1990). El primer contacto que tiene un visitante con una vista específica ya rara vez se efectúa de manera virginal, sin el condicionamiento de marcadores (MacCannell, 2003). Por ello, es importante indagar de qué modo se representa específicamente la cultura llanera colombiana con el fin de atraer la llegada de turistas a Villavicencio; y en especial, cuáles son los mecanismos significantes que se manifiestan en los discursos de promoción.

Los videos que incentivan a concurrir a los eventos culturales de la zona constituyen un fragmento de interés para complementar el análisis ya brindado a partir de las ciberpáginas. En particular, se tomó en esta ocasión el Festival Llanero de Villavicencio, puesto que es el único que pertenece a la ciudad y, por ende, su gestión corresponde a las autoridades municipales (el Torneo Internacional del Joropo y la Feria Expomalocas son administrados, en cambio, por la Gobernación del Departamento del Meta).

Desde 2012 se lleva a cabo este evento que procura "ofrece(r) a los habitantes y visitantes de la capital del Meta, la posibilidad de disfrutar un inicio de diciembre alegre, variado (...) donde la cultura y costumbres llaneras son exhibidas con orgullo" (Festival Llanero, 2016).

Sin embargo, ese universo queda descrito de modo acotado en las distintas piezas audiovisuales, ya que se aluden a una serie de prácticas que tienden a inscribirse en alguna de estas tres grandes áreas semánticas:

- Ganadería, por medio del coleo, la cabalgata, la equitación y la feria equina. Faenas que coadyuvan a construir al llanero como un jinete excepcional, con habilidades que lo asimilan con las figuras míticas del cowboy norteamericano y el gaucho de las pampas rioplatenses.

- Gastronomía, con "sabores exquisitos", ilustrada mediante imágenes de la carne asada en varas y de la hayaca.

- Música, canto y baile pertenecientes al joropo, cuyo carácter festivo se patentiza por la articulación de las sonrisas, giros y zapateo de los bailadores, junto con las maracas y las arpas en acción. También hacen presencia estelar algunos de los artistas que después formaron parte del evento, como Wilton Gámez, Jhon Onofre, el Cholo Valderrama, entre otros, quienes invitan al público a asistir, al sostener con sus reconocidas voces las diversas imágenes que buscan enaltecer la tradición. 
Muy poco de lo que se manifiesta en los breves videos se desmarca de esa malla que compendia la identidad folklórica llanera; apenas una referencia visual rápida al ciclismo de montaña, un deporte apreciado a nivel nacional pero inverosímil en este marco fuertemente convencional. Su inserción es llamativa porque al mismo tiempo se omite cualquier referencia a las artes plásticas llaneras -contempladas igualmente en el festival a través de una muestra de artesanías-, así como de imágenes de la movida nocturna.

Luego, habría que mencionar, también como discordantes, los motivos que remiten tanto a la ciudad como a la naturaleza, donde imperan la vegetación y los animales; escenarios que, pese a su cercanía, no parecen afines a la figura del avezado jinete, como sucede con la sabana. De hecho, las imágenes del conjunto, muchos montados a caballo sobre el asfalto urbano, despierta connotaciones de irrupción, mientras los humedales se exhiben como un telón de fondo ajeno. Asoma aquí un problema comunicacional de orden semántico, ya que la mezcla de momentos que se asocian claramente con el festival con otros que describen la geografía de Villavicencio podría generar confusión entre los turistas potenciales que carecen de información sobre el oriente colombiano.

Respecto a la dimensión retórica, se apela a estrategias clásicas, frecuentes en esta clase de discursos. El collage metonímico de situaciones ligadas con el evento/lugar ensambladas por una banda musical, el ligero juego del blanco y negro con el color, la pantalla partida; la reiteración excesiva de las principales actividades a través de la imagen, la canción y la escritura, y la locución en off contribuyen a reforzar la figuración altamente estereotipada del llanero.

Por su contenido, estos videos pueden persuadir más bien a un destinatario de origen colombiano, en especial de la zona, quien ya conoce y disfruta de esa cultura alegre y aferrada a la tierra; un visitante con valores tradicionales, de movimientos diurnos, que se restringe a asumir el rol de espectador de todo lo que ofrece el evento con una participación pasiva y absorción de lo que es presentado en el festival.

En cambio, la propuesta resulta poco amigable para el turista extranjero. Hay un grado de presuposición y de falta de claridad que lo aleja. Además, aunque se lo mencione al pasar en alguna de las canciones, se halla ausente icónicamente, pues de acuerdo con el verosímil social, los visitantes retratados se identifican por sus facciones con la población local. Quizás atrape a aquel que les seduzca las costumbres pintorescas, con predilección por las películas "del lejano oeste".

Por su parte, la Alcaldía de Villavicencio se erige como un enunciador-marca tradicional, amistoso, orgulloso de la cultura de la región, aunque con escasa pericia en la faceta comunicacional. Estos videos, sin el acompañamiento de paratextos que informen acerca de las diversas atracciones y comodidades de la ciudad/ región, así como de su historia, tienden a suscitar distancia en aquellos que ignoran ese marco interpretativo esencial.

En conclusión, no se establecería a priori una relación directa entre este corpus y las motivaciones del viaje. Araújo (2015) destaca que el componente audiovisual brinda la oportunidad de descubrir y trasladarse a otros escenarios; no obstante, debido en primer término a la configuración retórica de estos videos, se sabotea aquí dicha vía.

\section{Percepción del destino a partir de la información contenida en las páginas web}

El individuo antes de convertirse en turista es internauta, de allí la importancia de conocer sus percepciones sobre la ciudad antes de iniciar su experiencia con el destino. De este modo se evidencia que para el 61\% de ellos, la valoración general de percepción alcanza el nivel de buena; y el 36\% indica que la misma es muy buena, tal como se expone en la tabla 3. Los datos indican que, a pesar de los problemas de índole comunicacional expuestos anteriormente, la ciudad tiene una adecuada capacidad de atracción por la información presentada al turista internacional, alcanzando un $97 \%$ de percepción favorable. 
TABLA 3.

Percepción a priori del destino

\begin{tabular}{lrrrrrrrr}
\hline & \multicolumn{6}{c}{ Percepción de la ciudad } & Total \\
\cline { 2 - 8 } Fuente de información & Mala & $\%$ & Buena & $\%$ & $\begin{array}{r}\text { Muy } \\
\text { buena }\end{array}$ & $\%$ & \\
\hline Página web de Villavicencio & 0 & $0 \%$ & 5 & $15 \%$ & 5 & $15 \%$ & 10 \\
\hline Web de viajes & 1 & $3 \%$ & 1 & $3 \%$ & 0 & $0 \%$ & 2 \\
\hline $\begin{array}{l}\text { Página web de Villavicencio y } \\
\text { otras fuentes }\end{array}$ & 0 & $0 \%$ & 4 & $12 \%$ & 6 & $18 \%$ & 10 \\
\hline Web de viajes y otras fuentes & 0 & $0 \%$ & 10 & $30 \%$ & 1 & $3 \%$ & 11 \\
\hline Total & 1 & $3 \%$ & 20 & $61 \%$ & 12 & $36 \%$ & 33 \\
\hline
\end{tabular}

Fuente: elaboración propia

Debido a que la información contenida en las páginas web promocionales está dirigida a un segmento muy genérico, se procedió a comprobar la hipótesis 1, que analiza la relación entre la edad y su nivel de percepción, tal como se detalla en la tabla 4.

TABLA 4.

Relación entre edad del turista y la percepción de la ciudad comunicada páginas web

\begin{tabular}{lr}
\hline Coeficiente de correlación Tau-c de Kendall & 0,303 \\
\hline Valor Sig. (bilateral) & 0,060 \\
\hline Muestra & 33 \\
\hline
\end{tabular}

Fuente: elaboración propia

Los resultados demuestran que el indicador de correlación es bajo y no significativo en la relación de las variables medidas. Por tanto, se rechaza la primera hipótesis planteada, siendo la percepción de Villavicencio una variable independiente de la edad del turista internacional que la visita. Ello se contrapone a los hallazgos de Suárez (2012), quien a partir de su revisión determina que la edad como característica sociodemográfica de los individuos, entre otras, "es una variable interna que ostenta un protagonismo especial en la percepción de los destinos turísticos” (p. 15).

\section{La evaluación de la oferta turística promocionada}

En términos generales, previo a la llegada a Villavicencio, la percepción del destino obtuvo una calificación positiva del $97 \%$ de los turistas internacionales. No obstante, cuando llegaron a la ciudad realizaron un proceso de evaluación de la oferta turística anunciada mediante las páginas web. La tabla 5 permite observar que se mantienen estables y cercanos al 60\% los porcentajes de aquellos turistas que tenían una percepción positiva de Villavicencio, pero aquellos turistas que poseían la percepción más alta encontraron una disonancia entre el contenido de las páginas web y las características reales de la oferta. El análisis estadístico permite determinar que el porcentaje de la oferta turística calificada como negativa alcanzó el $15 \%$, y la evaluada como muy buena solo alcanzó el 21\%. Estas cifras motivan a la reflexión en torno a que la promoción en las páginas web con miras a posicionar a Villavicencio como un destino internacional no es la más adecuada. 
TABLA 5.

Calificación de la oferta turística anunciada

\begin{tabular}{|c|c|c|c|c|c|c|c|}
\hline \multirow[b]{2}{*}{ Fuente de información } & \multicolumn{6}{|c|}{ Calificación } & \multirow[b]{2}{*}{ Total } \\
\hline & Mala & $\%$ & Buena & $\%$ & $\begin{array}{r}\text { Muy } \\
\text { Buena }\end{array}$ & $\%$ & \\
\hline Página web de Villavicencio & 1 & $3 \%$ & 5 & $15 \%$ & 4 & $12 \%$ & 10 \\
\hline Web de Viajes & 1 & $3 \%$ & 2 & $6 \%$ & 0 & $0 \%$ & 3 \\
\hline $\begin{array}{l}\text { Página web de Villavicencio y } \\
\text { otras fuentes }\end{array}$ & 2 & $6 \%$ & 5 & $15 \%$ & 3 & $9 \%$ & 10 \\
\hline Web de Viajes y otras fuentes & 1 & $3 \%$ & 9 & $27 \%$ & 0 & $0 \%$ & 10 \\
\hline Total & 5 & $15 \%$ & 21 & $64 \%$ & 7 & $21 \%$ & 33 \\
\hline
\end{tabular}

Fuente: elaboración propia

La tabla anterior deja en evidencia que, del total de páginas web consultadas por los turistas, ninguna está exenta de una mala calificación. Por tanto, se trata de un indicador que debe analizarse con mayor profundidad, puesto que cerca del $10 \%$ de estas malas calificaciones tiene como fuente la página web de Villavicencio, la cual es el sitio oficial del ente público encargado de la promoción turística de la ciudad. Esto significa que su efectividad como instrumento de promoción es baja.

\section{Satisfacción del turista}

Tras la permanencia en el destino, el consumidor turístico tendrá diferentes niveles de satisfacción con respecto a la inversión realizada y a las expectativas generadas según su experiencia vivida. Estas expectativas se asocian con las imágenes a las que ha estado expuesto el individuo en el proceso previo a su desplazamiento. Así, al evaluar la satisfacción del turista internacional se evidencia que los resultados son coherentes con el nivel de calificación de la oferta real presentada en la tabla 5. Junto a estos datos, la tabla 6 refleja que el 18\% de los encuestados calificó su experiencia en el nivel de insatisfecho. Dicho porcentaje es cercano al 15\% que calificó como mala la oferta encontrada.

TABLA 6.

Satisfacción con la experiencia turística

\begin{tabular}{|c|c|c|c|c|c|c|c|}
\hline \multirow[b]{2}{*}{$\begin{array}{l}\text { Fuente de } \\
\text { información }\end{array}$} & \multicolumn{6}{|c|}{ Valoración } & \multirow[b]{2}{*}{ Total } \\
\hline & Insatisfecho & $\%$ & Satisfecho & $\%$ & $\begin{array}{r}\text { Muy } \\
\text { satisfecho }\end{array}$ & $\%$ & \\
\hline $\begin{array}{l}\text { Página web de } \\
\text { Villavicencio }\end{array}$ & 1 & $3 \%$ & 5 & $15 \%$ & 4 & $12 \%$ & 10 \\
\hline Web de viajes & 0 & $0 \%$ & 2 & $6 \%$ & 0 & $0 \%$ & 2 \\
\hline $\begin{array}{l}\text { Página web de } \\
\text { Villavicencio y } \\
\text { otras fuentes }\end{array}$ & 1 & $3 \%$ & 5 & $15 \%$ & 4 & $12 \%$ & 10 \\
\hline $\begin{array}{l}\text { Web de viajes y } \\
\text { otras fuentes }\end{array}$ & 4 & $12 \%$ & 7 & $21 \%$ & 0 & $0 \%$ & 11 \\
\hline Total & 6 & $18 \%$ & 19 & $58 \%$ & 8 & $24 \%$ & 33 \\
\hline
\end{tabular}


Los turistas que manifestaron quedar satisfechos con su experiencia representan el $58 \%$, dato coherente con el $64 \%$ de la calificación de la infraestructura considerada como buena, y finalmente el $24 \%$ de los encuestados se encuentran en el nivel de satisfacción más alto. Esto significa que a uno de cada cuatro turistas que tuvieron como fuente de información las páginas web, su estadía en Villavicencio les permite retornar a su país de origen muy satisfechos. Un buen resultado para continuar con las evaluaciones de satisfacción y realización de los ajustes necesarios para mantener y aumentar en el tiempo este indicador.

Finalmente, respecto a la hipótesis 2 , los resultados que se presentan en la tabla 7 demuestran que no existe significatividad alguna en el índice de correlación entre la edad y el nivel de satisfacción alcanzado en el destino. Tal resultado coincide con el trabajo de Ari et al. (2014), quienes en su investigación sobre Kuala Lumpur no hallan evidencia que certifique los efectos positivos en la relación percepción-satisfacción del turista menor de 40 años.

TABLA 7.

Relación edad - satisfacción con la experiencia turística

Coeficiente de correlación Tau-c de Kendall

\begin{tabular}{lr}
\hline Sig. (bilateral) & 0,124 \\
\hline Muestra & 33 \\
\hline
\end{tabular}

Fuente: elaboración propia

Frente a los datos anteriores se puede afirmar que los turistas internacionales que visitan Villavicencio, y tuvieron como fuente de información las distintas páginas web públicas y privadas, alcanzan los niveles de satisfacción anteriormente descritos sin incidir la edad que tengan. Por ello, la estrategia promocional de comunicación puede plantearse en términos amplios, sin enfatizar en algún grupo etario en el cual el mensaje se centre en la atracción para que realicen las actividades tipificadas por Pine y Gilmore (1998).

\section{Conclusión}

La vinculación que se efectúa en el presente artículo entre un análisis semiótico y uno cuantitativo genera conexiones que permiten aclarar los modos en que el visitante extranjero razona y actúa. Sin embargo, al mismo tiempo el cotejo evidencia desajustes que desencadenan nuevos interrogantes e investigaciones futuras.

A la luz de los resultados obtenidos, se concluye que las páginas web analizadas dan a conocer una serie de propuestas comunicacionales en torno a la naturaleza y a la cultura llanera que posicionan a Villavicencio como un destino interesante para visitar, en especial para los segmentos pertenecientes a otras regiones de Colombia, que buscan la aventura y el exotismo. Caso contrario sucede con la promoción del destino a nivel internacional: en este caso, se detectan los inconvenientes más notorios en los sitios web oficiales, los cuales intentan persuadir al turista extranjero sin demasiada eficacia, una inferencia en la que coinciden la indagación semiótica y el trabajo de campo.

En cambio, en lo que disienten ambas aproximaciones de manera clara es en la efectividad que poseen en general estas páginas web en atraer al visitante extranjero. Los guarismos demuestran que imperan las calificaciones positivas entre los encuestados, en contraste con el análisis semiótico que destaca las significativas deficiencias comunicacionales de esos textos. Tal divergencia amerita una alerta para el sector turístico villavicense: corre rápidamente gran peligro de perder su buena posición si surge un competidor territorial cercano que ofrezca similares atractivos mediante una estrategia comunicacional seductora y consistente que atraiga al consumidor turístico internacional. 


\section{Referencias}

Aguiar, J. (2012). Organización comunitaria para un turismo emergente. Sistematización de experiencias. Gestión Turistica, (17), 37-54.

Araújo, N. (2015). De la economía de experiencias al turismo experiencial. Las series de ficción como creadoras de experiencias e inductoras a la visita de destinos turísticos. PASOS. Revista de Turismo y Patrimonio Cultural, 13(4), 959-964.

Ari, N. R., Subramoniana, H., y Pahlevan, S. S. (2014). Tourists' perceptions of destination travel attributes: An application to International tourists to Kuala Lumpur. Procedia - Social and Behavioral Sciences, 144, 403-411. h ttps://doi.org/10.1016/j.sbspro.2014.07.309

Bhatnagar, A., y Ghose, S. (2004). Segmenting consumers based on the benefits and risks of Internet shopping. Journal of Business Research 57, 1352 - 1360. 10.1016/S0148-2963(03)00067-5

Bordas, E. (2003). Hacia el turismo de la sociedad de ensueño: nuevas necesidades de mercado. Ponencia presentada en Inauguración del primer semestre del curso 2002-2003 de los Estudios de Economia y Empresa de la UOC, Bellaterra. Recuperado de http://www.uoc.edu/dt/20219/index.html

Burgess, L., Parish, B., y Alcock, C. (2011). To what extent are regional tourism organizations (RTOs) in Australia leveraging the benefits of web technology for destination marketing and eCommerce? Electronic Commerce Research, 11(3), 341-355. http://dx.doi.org/10.1007/s10660-011-9077-1.

Butler, R. (1980). The concept of a tourist area cycle of evolution: implications for management of resources. The Canadian Geographer, 24(2). 5-12. 10.1111/j.1541-0064.1980.tb00970.x.

Cabanilla, E. A., y Gentili, J. O. (2015). Características de las páginas de la Internet de turismo comunitario en países de América. Una aproximación desde el análisis de contenidos y la cartografía temática. PASOS. Revista de Turismo y Patrimonio Cultural, 13(1), 157-174.

Camprubí, R., Guia, J., y Comas, J. (2009). La formación de la imagen turística inducida: un modelo conceptual. PASOS. Revista de turismo y patrimonio cultural, 7(2), 255-270.

Castillo, P. M., y Castaño, M. C. (2015). La promoción turística a través de técnicas tradicionales y nuevas. Una revisión de 2009 a 2014. Estudios y Perspectivas en Turismo, 24(3), 737-757.

Chen, P. J., y Kerstetter, D. L. (1999). International student's image of rural Pennsylvania as a travel destination. Journal of Travel Research, 37(3), 256-266. 10.1177/004728759903700307

Chiou, W. B., Wan, C. S., y Lee, H. Y. (2008). Virtual experience vs. brochures in the advertisement of scenic spots: how cognitive preferences and order effects influence advertising effects on consumers. Tourism Management, 29(1), 146-50. 10.1016/j.tourman.2007.03.016

Csikszentmihalyi, M. (1975). Beyond boredom and anxiety. San Francisco: Jossey bass publishers.

Cuenca, M. C., y Prat, A. (2012). Ocio experiencial: antecedentes y características. ARBOR. Ciencia, Pensamiento y Cultura, 188(754), 265-281. 10.3989/arbor.2012.754n2001

De Rojas, C., y Camarero, C. (2008). Visitors experience, mood and satisfaction in a heritage context: Evidence from an interpretation center. Tourism management, 29(3), 525-537. https://doi.org/10.1016/j.tourman.2007.06.004

Ejarque, J. (2005). Destinos turisticos de éxito: diseño, creación, gestión y marketing. Madrid: Pirámide.

Festival Llanero. (2016). $5^{\circ}$ Festival Llanero de Villavicencio. Recuperado de http://festivalllanero.com/

Funes, M. (2015, 4 de abril). Diez tendencias del turismo mundial. $A B C$. Recuperado de http://www.abc.es/econom ia/20150403/abci-tendencias-turismo-mundial-201504030220.html

Galí, N., y Donaire, J. A. (2005). The social construction of the image of Girona: A methodological approach. Tourism Management, 26(5), 777-785. 10.1016/j.tourman.2004.04.004

Garay, T. L. (2007). El ciclo de evolución del destino turistico. Una aproximación al desarrollo histórico del turismo en Cataluña (Tesis doctoral). Universidad Autónoma de Barcelona, España.

Greimas, A. (1976). Semántica estructural. Madrid: Gredos. 
Jiménez, H. V., Coca, J. L., Gutiérrez, M., y Fernández, A. (2016). Determinants of the expenditure done by attendees at a sporting event: The case of World Padel Tour. European Journal of Management and Business Economics, 25(3), 133-141. https://doi.org/10.1016/j.redeen.2016.05.002

Johnson, B., y Onwuegbuzie, A. (2004). Mixed methods research: A research paradigm whose time has come. Educational Researcher, 33(7), 14-26.

Kotler, P., Bowen, J., y Makens, J. (2004). Marketing para turismo. Madrid: Pearson Educación.

MacCannell, D. (2003). El turista: Una nueva teoría sobre la clase ociosa. Barcelona: Editorial Melusina.

Marujo, N. (2012). Imagen y promoción de los destinos turísticos en internet. El caso de los municipios de la Isla Madeira. Estudios y Perspectivas en Turismo, 21(4), 825-837.

Medina, C., Rey, M., y Rufín, R. (2010). Imagen de los destinos turísticos urbanos y lealtad del turista...: ¿Actitud o comportamiento? Estudios y perspectivas en turismo, 19(2), 279-298.

Mehmetoglu, M., y Normann, Ø. (2013). What influences tourists' overall holiday experience? Tourism company products versus destination products. European journal of tourism Research 6(2), 183-191.

Mendes, G., Biz, A., y Gândara, J. M. (2013). Innovación en la promoción turística en medios y redes sociales. Un estudio comparativo entre destinos turísticos. Estudios y Perspectivas en Turismo, 22(1), 103-119.

Miossec, J. M. (1977). L'image touristique comme introduction à la géographie du tourisme. Annales de Géographie, 86(473), 55-70.

Pantano, E., y Servidio, R. (2011). An exploratory study of the role of pervasive environments for promotion of tourism destinations. Journal of Hospitality and Tourism Technology, 2(1), 50-65. http://dx.doi.org/10.1108/1757988 1111112412

Pine, B. J., y Gilmore, J. H. (1998). Welcome to experience economy. Harvard Business Review, 74(6), 97-105.

Quadri-Felitti, D., y Fiore, A. M. (2012). Experience economy constructs as a framework for understanding wine tourism. Journal of Vacation Marketing, 18(1), 3-15. 10.1177/1356766711432222

Rivera, M. (2013). El turismo experiencial como forma de turismo responsable e intercultural. Córdoba: Universidad de Córdoba.

Segre, C. (1985). Principios de análisis del texto literario. Barcelona: Crítica.

Serre, D. L., y Chevalier, C. (2012). Marketing travel services to senior consumers. The Journal of Consumer Marketing, 29(4), 262-270. http://dx.doi.org/10.1108/07363761211237335.

Steimberg, O. (1993). Semiótica de los medios masivos. Buenos Aires: Atuel

Su, C. J., Lebrun, A. M., Bouchet, P., Wang, J. R., Lorgnier, N., y Yang, J. H. (2016). Tourists' participation and preference-related belief in co-creating value of experience: a nature-based perspective. Service Business, 10(4), 823-846. 10.1007/s11628-015-0292-z

Suárez, M.J. (2012). El efecto moderador de la procedencia cultural del turista en la percepción de la imagen del destino. Sociologia: Revista da Faculdade de Letras da Universidade do Porto, 23, 11-35.

Urry, J. (1990). The Tourist Gaze: Leisure and Travel in Contemporary Societies. Londres: Editorial Sage.

Verón, E. (1985). L'analyse du 'contrat de lecture': une nouvelle méthode pour les études de posiciotionnement des supports presse. En AA. VV., Les Médias Espériences, recherches actuelles, aplications (pp. 203-229). París, Francia: IREP.

Wang, C., y Yang, H. (2008). Passion for online shopping: The influence of personality and compulsive buying. Social Behavior and Personality: An internationaljournal, 36(5), 693-706. https://doi.org/10.2224/sbp.2008.36.5.693

\section{Notas}

* Esta investigación fue financiada por la Universidad de los Llanos y forma parte de los resultados del proyecto "Determinación de las estrategias que generan el posicionamiento de Villavicencio como destino turístico internacional" realizada durante 2015 y 2016. Incluye los aportes del profesor Centocchi, quien integra los proyectos "Apropiaciones 
móviles de la ficción narrativa literaria y cinematográfica" (UNA) y "Letra, imagen, sonido. Plataformas y redes sociales: relaciones entre mediatización, espacio urbano y cultura” (UBACyT).

\section{Licencia Creative Commons CC BY 4.0}

Cómo citar este artículo: Otero Gómez, M. C., Centocchi, C. F., y Giraldo Pérez, W. (2018). Comunicación de un destino experiencial a través de las páginas web. Análisis de Villavicencio - Colombia. Signo y Pensamiento, 37(73). https://doi.org/10.11144/Javeriana.syp37-73.cdep 